\title{
Endogenous Market Structures and Contract Theory. Delegation, principal-agent contracts, screening, franchising and tying
}

\section{Federico Etro}

Ca' Foscari University of Venice

First Draft: June 2010

\begin{abstract}
I study the role of unilateral strategic contracts for firms active in markets with price competition and endogenous entry. Traditional results change substantially when the market structure is endogenous rather than exogenous. They concern 1) contracts of managerial delegation to non-profit maximizers, 2) incentive principal-agent contracts in the presence of moral hazard on cost reducing activities, 3) screening contracts in case of asymmetric information on the productivity of the managers, 4) vertical contracts of franchising in case of hold-up problems and 5) tying contracts by monopolists competing also in secondary markets. Firms use always these contracts to strengthen price competition and manage to obtain positive profits in spite of free entry.
\end{abstract}

Keywords

Strategic delegation, Incentive contracts, Screening contracts, Franchising, Tying, Endogenous market structures.

JEL Codes

L11, L13, L22, L43.

Address for correspondence:

Federico Etro

Department of Economics

Ca' Foscari University of Venice

Cannaregio 873, Fondamenta S.Giobbe

30121 Venezia - Italy

Phone: (++39) 3294464955

Fax: (++39) 0412349176

e-mail: fetro@intertic.org

This Working Paper is published under the auspices of the Department of Economics of the Ca' Foscari University of Venice. Opinions expressed berein are those of the authors and not those of the Department. The Working Paper series is designed to divulge preliminary or incomplete work, circulated to favour discussion and comments. Citation of this paper should consider its provisional character.

The Working Paper Series
is availble only on line
(www.dse.unive.it/pubblicazioni)
For editorial correspondence, please contact:
wp.dse@unive.it

Department of Economics

Ca' Foscari University of Venice

Cannaregio 873, Fondamenta San Giobbe

30121 Venice Italy

Fax: ++39 0412349210 


\section{Introduction}

Contractual arrangements between different stakeholders of a firm are crucial for the efficiency of its production process and for its profitability. Contract theory has widely studied these arrangements within a firm in the presence of informational asymmetries (Laffont and Martimort, 2002), contractual incompleteness (Hart, 1995) or other inefficiencies in principalagent relations. ${ }^{1}$ However, contract theory has less often investigated the relation between contracts within a firm and competition with other firms: some important works have focused on simple delegation games in duopolies (starting with Fershtman and Judd, 1987, and Bonanno and Vickers, 1988), but limited attention has been paid to principal-agent contracts for firms competing in markets whose structure is endogenous, that is where entry of firms is endogenous. This paper analyzes this issue focusing on the following basic question: how competitive pressure affects the optimal contracts and how these contracts affect the resulting market structure? ${ }^{2}$ I answer this question through a rather general model in which a firm adopts optimal contractual arrangements with some stakeholders (its manager, its retailers, its customers,..) before competing with other firms.

The characterization of the optimal contracts can be relevant also for empirical and policy analysis. On the empirical front, I emphasize the crucial impact of endogenous entry threats on the nature of the optimal contracts: for instance, one should expect the emergence of sale incentives, high-powered incentive mechanisms and strong bonuses inducing extra effort for the managers of firms which face strong entry threats, and not (or less) for firms without such threats. In line with these findings, recent works have emphasized a weak but positive relation between different measures of competition and incentives to promote effort (Cuñat and Guadalupe, 2005; Bloom and Van Reenen, 2007; Czarnitzki et al., 2010), but further research could fruitfully focus on the precise impact of entry pressure on the contractual arrangements.

On the policy front, I analyze the general welfare implications of strategic contracts and, in particular, the antitrust implications of vertical contracts and tying contracts adopted by a firm facing competition respectively in the downstream market and in the market for the

\footnotetext{
${ }^{1}$ See Bolton and Dewatripont (2005) for a wide survey.

${ }^{2} \mathrm{~A}$ second question one may ask is what should be the equilibrium structure of the market and of the contracts when all firms adopt contractual arrangements and market strategies in equilibrium. For an investigation of this issue in the presence of principal-agent contracts with asymmetric information I refer to Martin (1993), Martimort (1996) and Etro and Cella (2010).
} 
tied good. Also here, the presence of endogenous entry threats is crucial, because it leads to the adoption of contractual arrangements that are aimed at strengthening price competition without predatory purposes. Contrary to what happens in models with an exogenous number of firms (first analyzed by Bonanno and Vickers, 1988, and Whinston, 1990), franchising contracts and tying cannot lead to monopolization of new markets and they actually tend to reduce prices and improve welfare. As I will show, this generates conclusions that are in radical contrast with the post-Chicago approach to vertical restraints and exclusionary contracts, and that can change our perspective on relevant antitrust cases.

To introduce our theoretical framework and establish the link with the traditional literature on strategic contracts, let us consider basic price competition betwen two firms. It is well known that in a price duopoly a profit-maximizing firm can increase profitability through a particular form of strategic delegation: this requires a commitment to adopt accommodating strategies which relax competition and increase prices and profits of both firms. The important works by Sklivas (1987) and Fershtman and Judd (1987) have emphasized the gains from delegating decisions on prices to managers with negative sale incentives. Raith (2003) has suggested that, in the presence of moral hazard of the managers, there are gains from incentive schemes (à la Holmstrom and Milgrom, 1991) with a low variable (outputrelated) compensation that generates low effort and softens competition. The same occurs in the presence of asymmetric information on the productivity of the managers faced with optimal screening contracts. Bonanno and Vickers (1988) and Rey and Stiglitz (1995) have emphasized the gains from separation in two vertically related firms, where the upstream firm charges the downstream firm with a francise fee and a wholesale price above marginal cost once again to soften price competition. In the same spirit, Whinston (1990) has shown that, when a monopolist in a primary market is also active in a secondary duopolistic market, tying strengthens competition and can be profitable only to deter entry and monopolize the secondary market. These results are a consequence of strategic complementarity between price choices (Fudenberg and Tirole, 1984; Bulow et al., 1985; Gal-or, 1985): a strategic contract that induces the manager of a firm to increase its price, induces also the rival firm to increase its price and therefore it generates higher profits for the former and, even more, for the latter. Unfortunately, all these results are not robust to changes in the form of competition, and they break down when the two firms compete in quantities rather than in prices: this leaves the literature on strategic contracts with ambiguous results.

As suggested in Etro (2006), a limit of the literature on strategic commitments is that the 
number of competitors (two in most applications) is pre-determined and independent from the market outcome: this is in stark contrast with most real markets, where entry is attracted by the profitable opportunities left over by the active firms and by expectations on future profitability. Even in concentrated markets where entry cannot be regarded as free (i.e. easy and immediate) because of the presence of large sunk costs, the number of active firms can be often seen in the medium-long run as endogenously determined by the profit conditions taking into account the exogenous (or endogenous) entry costs (Sutton, 1991). This paper shows that when a firm is active in such a market, that is where the number of competitors (two as above, or more) is endogenous, the cited contractual commitments can still play a role, but in a radically different way. Our results for markets with price competition and endogenous entry can be summarized as follows:

- operative strategies should be always delegated to managers whose objective function is a weighted average of profits and sales, and we characterize the optimal (linear) sale incentives;

- in the presence of moral hazard, managerial compensation should provide high-powered incentives with a larger variable compensation than the other firms, and we derive the optimal strategic incentive payments in a model à la Holmstrom-Milgrom;

- in the presence of asymmetric information, managerial payment schedules should induce higher effort than the other firms, and we derive the optimal screening contracts;

- vertical separation between an upstream producer and a downstream retailer should always entail wholesale prices below marginal costs for the downstream firm, and we determine the optimal franchising contracts (and verify the consequences of hold up problems on the same optimality of vertical separation);

- tying contracts can be effective devices to gain profits in a secondary market without fully deterring entry, and we determine the conditions for the optimality of tying.

The underlying reason of these results is that the strategic purpose of any contract changes when entry in the market is endogenous. Contractual arrangements that lead to a price increase are ineffective because they attract entry and reduce sales and profits. To the contrary, any contractual commitment to implement a price reducing strategy is effective because it limits the profitability of entry and increases the market share and the profits of the firm. This motivates positive sale incentives and managerial compensations that promote cost reducing activities. At the same time, the nature of the optimal franchising contracts radically changes when entry of downstream firms is free: low prices can only be forced through wholesale prices below the marginal cost (which are welfare enhancing). Finally, 
tying becomes a useful strategy because it strengthens competition, increases sales in the secondary market and can increase profits of the bundling firm even without inducing full entry deterrence (but increasing welfare).

The nature of these optimal strategic contracts matches what one would obtain if the same firm was engaged in quantity competition (with strategic substitutability) rather than price competition, dissolving the traditional ambiguity associated with the optimal strategic contracts: ${ }^{3}$ when the market structure is endogenous, under both price and quantity competition it is optimal to commit to an aggressive strategy with appropriate contracts. ${ }^{4}$

In this paper, I characterize the role of simple strategic contracts in a number of classic contexts, derive the optimal unilateral contracts (under our functional assumptions) and characterize the associated equilibrium market structure. The applications concern the cited models of contracts with managers or customers, but elsewhere I have analyzed contracts with other stockholders, as the debt contracts (Etro, 2010). In most of the analysis, my focus is on unilateral contracts to emphasize the nature of the incentives that each single firm has, and how this changes in markets with exogenous and endogenous structures. Moreover, the analysis of unilateral commitments is the relevant one when we want to study the consequence of the behavior of a single dominant firm, which has crucial implications for antitrust policy. Nevertheless, the analysis of equilibria in which more or all firms can adopt the same contractual commitments can be developed along traditional lines: in a Nash equilibrium the nature of the equilibrium contracts would be the same as that of the optimal unilateral contracts characterized here - for instance, see Etro (2010) for the Nash equilibrium debt contracts adopted by multiple firms in a market with endogenous entry.

The paper is organized as follows. Section 2 introduces the basic framework of Bretrand competition for all the subsequent applications. Section 3 presents the simplest one, concerning profit-maximizing delegation to managers that do not maximize profits. Section 4 develops the topic of managerial compensation through a basic principal-agent model of moral hazard. Section 5 extend the analysis to the case of adverse selection and screening

\footnotetext{
${ }^{3}$ A related message emerges in the model of Miller and Pazgal (2001), which shows that, when the set of incentive parameters available to the firms' owners is rich enough, the equilibrium prices, quantities and profits are the same regardless of whether the firms compete in prices or in quantities.

${ }^{4}$ Etro (2006) focuses on under- or over-investment in cost-reducing and demand enhancing activities. For some of the recent applications of the endogenous market structures approach to strategic commitments see Tesoriere (2008), Creane and Konishi (2009), Erkal and Piccinin (2010), Kováč et al. (2010) and Anderson et al. (2010).
} 
contracts. Section 6 applies our idea to franchising contracts between vertically separated firms. Section 7 analyzes tying contracts as a strategic device for a monopolist producing also for a secondary market. Section 8 concludes. The Appendix generalizes the model with a microfoundation of demand, extends it to Cournot competition and derives welfare results.

\section{Bertrand competition with endogenous entry}

Consider a market with price competition where entry is endogenous and occurs until profits are zero. Is there any contractual commitment that a firm can exploit to gain a competitive advantage and preserve positive profits? Contrary to what one may expect in a market where entry dissipates any profitable opportunities for the entrants, the answer is yes. More important, the kinds of contractual arrangements leading to these gains can be radically different from those emerging in traditional models with an exogenous number of competitors.

Let us consider competition in prices between $n$ firms producing differentiated goods. ${ }^{5}$ Direct demand of firm $i$ can be expressed as $D_{i}=D\left(p_{i}, P_{-i}\right)$ where $p_{i}$ is its price and the price aggregator $P_{-i}=\sum_{j=1, j \neq i}^{n} g\left(p_{j}\right)$ depends on all the other prices, with $D_{1}<0, D_{2}<0$ for some positive function $g(p)$ with $g^{\prime}(p)<0$. Substitutability between goods is guaranteed by the fact that the cross derivative $\partial D_{i} / \partial p_{j} \equiv \Delta_{i j}$ is always positive: $\Delta_{i j}=D_{2} g^{\prime}\left(p_{j}\right)>0$ for any $i$ and $j$. As an example, isoelastic preferences $\grave{a}$ la Dixit-Stiglitz generate direct demands nested in the above function, but one can also microfound in a similar way the Logit demand or other demand functions.

Each firm bears a fixed cost of entry $F>0$ and produces at a constant marginal cost $c$. Without any strategic contracts, net profits for firm $i$ are:

$$
\pi_{i}=\left(p_{i}-c\right) D\left(p_{i}, P_{-i}\right)-F
$$

Strategic complementarity holds, i.e. $\partial^{2} \pi_{i} / \partial p_{i} \partial p_{j}>0$, which requires $\Delta_{i j}>D D_{12} g^{\prime}\left(p_{j}\right) / D_{1}$.

All active firms choose their prices simultaneously. The equilibrium number of active firms $n$ is such that expected profits for the $n$-th entrant are zero. ${ }^{6}$ Therefore, in a symmetric situation, a first order condition $D(p, P)+(p-c) D_{1}(p, P)=0$ and a free entry condition

\footnotetext{
${ }^{5}$ We leave to the Appendix a microfoundation of such a model, which allows us to derive rigorous welfare comparisons, and a generalization to the case of competition in quantities.

${ }^{6}$ As usual we neglect the integer constraint on the number of firms, but we restrict the analysis to the set of parameters for which at least two firms remain active (this is the relevant case for small enough fixed costs and relevant product differentiation).
} 
$(p-c) D(p, P)=F$ would determine the equilibrium values of the common price $p$ and of the number of firms $n$ through the price aggregator $P=(n-1) g(p)$.

In this framework we will examine the impact of preliminary contractual arrangements between a firm, say firm $L$, and its partners (managers, retailers, customers, employers,..). Accordingly, the timing of our baseline model will be the following:

Stage 1: firm $L$ adopts a contractual arrangement to maximize its expected profits.

Stage 2: entry of other firms occurs until expected profits are non-negative.

Stage 3: all firms $j=1,2, \ldots, L, \ldots, n$ choose simultaneously their prices.

One can think of the contractual arrangements as strategic commitments that incumbents choose to optimize their productive organization in the long run. For simplicity we assume that a single firm adopts these arrangements, but we could easily extend the model to multiple incumbents adopting them. What is crucial is that there is always space for entry of a residual fringe of competitors: this justifies why entry of other firms takes place in the subsequent stage. Finally, pricing decisions can be seen as short run decisions and, therefore, they are taken at the last stage.

As we will verify (and contrary to what happens with a fixed number of firms), strategic contracts by a firm cannot affect the equilibrium price $(p)$, the demand $(D(p, P))$ and the net profits (zero) of the other firms in an endogenous market structure. Nevertheless, in the following sections we will analyze different strategic contracts and show how a firm can use them to obtain a comparative advantage over the other firms and gain strictly positive profits. $^{7}$

We remind the reader that our purpose is to verify how the endogeneity of market structures affects a number of traditional results on different strategic contracts, therefore each one of the following sections should be seen as a separate application in itself.

\section{Strategic delegation to non-profit maximizers}

In this section we consider the simplest example of strategic contract, introduced by Fershtman and Judd (1987) and Sklivas (1987). Suppose that the profit-maximizing equity holders

\footnotetext{
${ }^{7}$ Notice that endogenous entry overturns the second mover advantage pointed out by Gal-or (1985) for duopolies with strategic complementarity. While one could extend the analysis to a Nash equilibrium where all firms adopt similar strategic commitments, the analysis of a unilateral adoption is the simplest way to capture the nature of the mechanisms that we want to study.
} 
of firm $L$ delegate the pricing decision to a manager whose objective function depends on both profits and sales, for simplicity through a linear contract with explicit sale incentives. In such a case we can express the objective function of the management as: ${ }^{8}$

$$
\begin{aligned}
\Pi\left(p_{L}, P_{-L}, k\right) & =\pi_{L}+k \cdot p_{L} D\left(p_{L}, P_{-L}\right)= \\
& =\left[p_{L}(1+k)-c\right] D\left(p_{L}, P_{-L}\right)-F
\end{aligned}
$$

where the weight on sales $k$ is chosen ex ante by the firm's owner to maximize pure profits. All the other firms directly maximize profits. In this set up, Sklivas (1987) has shown that with $n=2$ it is optimal to choose $k<0$, that is negative sale incentives (contrary to what happens under competition in quantities). To verify this in our framework, notice that the duopoly equilibrium is characterized by the system of first order conditions determining the prices $p_{L}(k)$ for firm $L$ and $p_{j}(k)$ for the rival $j .{ }^{9}$ These prices are both decreasing in $k$ because of strategic complementarity. Given this, one can easily derive an implicit expression for the incentive scheme that maximizes profits $\Pi\left(p_{L}(k), g\left(p_{j}(k)\right), 0\right)$ as:

$$
k=\frac{-\left(p_{L}-c\right) \Delta_{L j} p_{j}^{\prime}(k)}{\left(p_{L}-c\right) \Delta_{L j} p_{j}^{\prime}(k)-c D_{1}\left(p_{L}, g\left(p_{j}\right)\right) p_{L}^{\prime}(k)}<0
$$

where we used the equilibrium pricing condition for firm $L$. Negative sale incentives are used to soften competition and maintain a low production while increasing prices and profits. The result generalizes to a larger exogenous number of firms.

Consider now the case of free entry in the market. For a given $k$, the endogenous market structure is characterized by the price $p_{L}$ for firm $L$, the price $p$ for all the other firms (by symmetry), and a number $n$ of firms. These equilibrium variables satisfy the respective first order conditions and the zero profit condition:

$$
\begin{gathered}
{\left[D\left(p_{L}, P_{-L}\right)+p_{L} D_{1}\left(p_{L}, P_{-L}\right)\right](1+k)=c D_{1}\left(p_{L}, P_{-L}\right)} \\
D(p, P)+p D_{1}(p, P)=c D_{1}(p, P) \quad \text { and } \quad(p-c) D(p, P)=F
\end{gathered}
$$

This system is characterized by a price $p$ and a price aggregator $P=(n-2) g(p)+g\left(p_{L}\right)$ which do not depend on the parameter $k$ - see the two equations in (4), and by a price of the

\footnotetext{
${ }^{8}$ Similar results emerge in case of quantity incentives as opposed to sale incentives (Vickers, 1985). The linear contract has been chosen only for tractability, and to emphasize the need of positive or negative sale incentives.

${ }^{9}$ The equilibrium conditions are $D\left(p_{L}, g\left(p_{j}\right)\right)+\left(p_{L}-c /(1+k)\right) D_{1}\left(p_{L}, g\left(p_{j}\right)\right)=0$ and $D\left(p_{j}, g\left(p_{L}\right)\right)+$ $\left(p_{j}-c\right) D_{1}\left(p_{j}, g\left(p_{L}\right)\right)=0$.
} 
firm $L$ given by $p_{L}=p_{L}(k)$, which is decreasing in $k-p_{L}^{\prime}(k)<0$ from (3). As a consequence, we can express the price index perceived by firm $L$ as:

$$
P_{-L}=(n-1) g(p)=P+g(p)-g\left(p_{L}(k)\right)
$$

which depends on $k$ only through the last term. Accordingly, a larger weight on sales in the compensation of the manager induces a lower price to expand sales, but does not affect the equilibrium prices of the other firms (while it reduces the endogenous number of firms). Given this, we can investigate the choice of the optimal strategic delegation through the problem:

$$
\max _{k}\left[p_{L}(k)-c\right] D\left[p_{L}(k), P+g(p)-g\left(p_{L}(k)\right)\right]-F
$$

where $p_{L}(k)$ satisfies the equilibrium system above. The optimality condition is:

$$
D\left(p_{L}, P_{-L}\right)+\left(p_{L}-c\right)\left[D_{1}\left(p_{L}, P_{-L}\right)-\Delta_{L L}\right]=0
$$

where $p_{L}=p_{L}\left(k^{*}\right)$ and we defined $\Delta_{L L}=D_{2}\left(p_{L}\left(k^{*}\right), P_{-L}\right) g^{\prime}\left(p_{L}\left(k^{*}\right)\right)>0$. Using the first order equilibrium condition (3) we can implicitly solve for the optimal strategic contract:

$$
k^{*}=\frac{\left(p_{L}-c\right) \Delta_{L L}}{-\left[D\left(p_{L}, P_{-L}\right)+p_{L} D_{1}\left(p_{L}, P_{-L}\right)\right]}>0
$$

The optimality of positive sale incentives derives from their strategic impact on entry. The term $\Delta_{L L}$ represents the indirect effect that an induced price change exerts on demand through the change in the endogenous number of entrants. The larger is the negative impact on entry of a price reduction of firm $L$ (due to the sale incentives), the larger is the increase in its demand, which makes it more profitable to adopt sale incentives (increases $k^{*}$ ). Summing up, we have:

Proposition 1. Under competition in prices with endogenous entry, a firm would always gain from delegating the pricing decisions to a manager whose objective function depends on both profits and sales (or from committing to positive sale incentives for the management).

As noticed before, in case of Bertrand competition between $n$ firms where the number $n$ is exogenously set, it was optimal for profit-maximizing equity holders to delegate the management to someone with negative sale incentives (Fershtman and Judd, 1987, and Sklivas, 1987). Contrary to this, when the market is endogenously characterized by the same number of firms, we obtain that it is optimal to delegate the management to someone who has incentives to maximize a weighted average of profits and sales, for instance through positive sale 
incentives. ${ }^{10}$ It is immediate to verify that the same result holds also under quantity competition with endogenous entry (because it is optimal to promote production and reduce the total production of the rivals). ${ }^{11}$ Therefore strategic delegation with positive sale incentives is always optimal in case of endogenous market structures.

This result can be related to the general principle of strategic commitments derived by Etro (2006) for which there is always a strategic incentive to adopt an investment $k$ which increases the marginal profitability of a higher production, or, equivalently in our framework, decreases the marginal profitability of a higher price (for the delegated agent). Here, we have $\Pi_{13}\left(p_{L}, P_{-L}, k\right)=D\left(p_{L}, P_{-L}\right)+p_{L} D_{1}\left(p_{L}, P_{-L}\right)$, which is negative in equilibrium, therefore the general principle applies. However, strategic delegation has obtained something more: through it, the firm has been able to exactly replicate the best pre-commitment equilibrium. We define this best equilibrium as the profit-maximizing equilibrium that can be obtained by firm $L$ with a direct commitment on the price before entry decisions and price decisions are taken by the other firms, namely the Stackelberg equilibrium with endogenous entry. ${ }^{12}$ To verify this, notice that such an equilibrium is characterized by a price of the followers $p$ and a corresponding price aggregator $P$ which depend on the price of the leader $p_{L}$ according to the same first order condition and the endogenous entry condition as in (4). Given this, the optimal price of the leader $p_{L}$ is the one chosen to maximize $\left(p_{L}-c\right) D\left(p_{L}, P_{-L}\right)$, where $P_{-L}=P+g(p)-g\left(p_{L}\right)$, which provides the same first order condition as in (5). All these conditions are met by the optimal strategic delegation $k^{*}$ derived above. This equivalence result is due to the absence of any costs in the enforcement of the desired contract: strategic delegation by firm $L$ delivers the same outcome as if firm $L$ were able to precommit on a price strategy. This leads one to derive the welfare implications of the delegation mechanism (see the Appendix for a rigorous and general proof): such a mechanism does not affect the equilibrium price aggregator and the price index, and therefore it does not affect consumer

\footnotetext{
${ }^{10}$ Analogously, we could consider the bargaining power of labor unions in setting wages at the firm level. Since this increases wages and induces the firm to increase prices, a firm would like to grant some bargaining power to the union when facing exogenous entry in the product market, but not when facing endogenous entry pressure.

${ }^{11}$ See the Appendix. This corresponds to what found by Fershtman and Judd (1987) for a duopoly in quantities. However, in that case a larger production was reducing the production of the rival, while in our case with endogenous entry it is reducing the number of rivals (with a constant individual production).

${ }^{12}$ The general characterization of Stackelberg equilibria with a first mover and endogenous entry of followers is developed in Etro (2008).
} 
surplus, but it increases profits (of firm $L$ ), and therefore total welfare.

The predictions of models on strategic delegation could be tested empirically. In particular, it is more likely to observe sale-based incentives or to observe stronger incentives, in markets with a heavy entry threat rather than in markets where there is no competitive pressure from outsiders. Moreover, controlling for the form of competition (or the form of strategic interaction as in Sundaram et al., 1996), one should find the distinction between price and quantity competition irrelevant for the adoption of these mechanisms in the first kind of markets (with high entry threats), but crucially relevant only for the second kind of markets (without entry threats). In a similar fashion, one could test the impact of the entry pressure on other incentive mechanisms adopted within firms (some of which will be discussed in the following sections). Czarnitzki et al. (2010) provide a first empirical investigation on the incentives to invest in R\&D: they find a strong impact of entry pressure on the incentives of the market leaders, in line with the strategic motive emphasized here. More empirical research in this direction is certainly needed.

Until now we assumed that the principal (the equity holder of the firm) could choose a parameter of a linear objective function of the agent (the manager). A more accurate description of a principal-agent relation requires the former to choose the optimal contract with the latter, a problem that becomes more complex in the presence of asymmetric information between the parties. The next two sections focus on this problem introducing costly effort by the manager.

\section{Incentive contracts and moral hazard}

Delegation through explicit incentive schemes is crucial in the presence of moral hazard of the managers. As shown by Raith (2003) the nature of these schemes depends on the intensity of competition: under price competition, lower variable compensations are used when the number of competitors increases. Moreover, these schemes can also be used to obtain a competitive advantage in the market, with lower variable compensations adopted to relax price competition.

Following the classic work of Holmstrom and Milgrom (1991, 1994), we will adopt a specification in which linear contracts are known to be optimal. Consider a manager receiving a wage $w$ and exerting effort $e$. The utility function is assumed to satisfy constant absolute 
risk aversion:

$$
u(w, e)=-\exp \left[-\gamma\left(w-\frac{d e^{2}}{2}\right)\right]
$$

where $\gamma>0$ is the coefficient of absolute risk aversion and the cost of effort has been assumed quadratic with $d$ positive parameter. The compensation includes a constant part, $\alpha$, and a part depending linearly on the observable performance, expressed in terms of unitary cost reductions of size $q$, according to a linear parameter $k$ :

$$
w=\alpha+k q
$$

The manager must be compensated enough to reach the reservation utility corresponding to an alternative riskless wage $\bar{w}$. The cost reduction is stochastic but positively related to effort, with:

$$
q=e+\varepsilon
$$

where $\varepsilon$ is a random variable which is normally distributed with zero mean and variance $\sigma^{2}$, and whose realization is known at the time of production. Therefore, the firm produces at the constant marginal cost $c-q=c-e-\varepsilon$ and the manager exerts effort $e$ to maximize the certainty equivalent payoff:

$$
C E=\alpha+k e-\frac{\gamma k^{2} \sigma^{2}}{2}-\frac{d e^{2}}{2}
$$

Now, imagine that a firm $i$ facing this incentive problem with its manager is also competing with other firms in the product market (the production/pricing decision is non-contractable and is taken at the competition stage simultaneously with the other firms to maximize profits). Effective profits are:

$$
\pi_{i}=D\left(p_{i}, P_{-i}\right)\left[p_{i}-\left(c-e_{i}-\varepsilon_{i}\right)\right]-\alpha_{i}-k_{i}\left(e_{i}+\varepsilon_{i}\right)-F
$$

whose equilibrium expectation is:

$$
\Pi\left(p_{i}, P_{-i}, k\right)=D\left(p_{i}, P_{-i}\right)\left(p_{i}-c+\frac{k_{i}}{d}\right)-\bar{w}-\frac{k_{i}^{2}}{2 d}-\frac{\gamma k_{i}^{2} \sigma^{2}}{2}
$$

where we used the incentive compatibility constraint $e_{i}=k_{i} / d$ and the individual rationality constraint $\bar{w}=\alpha_{i}+k_{i}^{2} / 2 d-\gamma k_{i}^{2} \sigma^{2} / 2$. Given the incentive contracts, all firms choose independently their prices to maximize expected profits, according to the condition:

$$
D\left(p_{i}, P_{-i}\right)+\left(p_{i}-c+\frac{k_{i}}{d}\right) D_{1}\left(p_{i}, P_{-i}\right)=0
$$


Let us now evaluate the optimal contract of a single firm, summarized by the parameter $k$, when the other competitors do not adopt incentive contracts, i.e. setting $k_{i}=0$ (later on, we will briefly consider the case in which all firms choose their optimal incentive contracts as well, showing that the spirit of our results is not affected).

Consider first the case of a duopoly. The system of first order conditions provides prices $p_{L}(k)$ for firm $L$ and $p_{j}(k)$ for the single competitor which are both decreasing in the incentive contract of firm $L$. Given this, one can easily derive an implicit expression for the optimal incentive scheme as:

$$
k=\frac{D\left(p_{L}, g\left(p_{j}\right)\right)+d\left(p_{L}-c\right) \Delta_{L j} p_{j}^{\prime}(k)}{1+\gamma d \sigma^{2}-\Delta_{L j} p_{j}^{\prime}(k)}
$$

where we used the equilibrium pricing condition for firm $L$. This optimal scheme differs from the Holmstrom-Milgrom (1991) contract because of the terms including $\Delta_{L j}=$ $D_{2}\left(p_{L}, g\left(p_{j}(k)\right)\right) g^{\prime}\left(p_{j}(k)\right)$, which reflect the negative impact of a price reduction of the competitor on demand. The optimal incentive scheme is still decreasing in the cost of effort $d$, in the degree of risk aversion $\gamma$ and in the randomness of the performance $\sigma^{2}$, but it is now reduced because more high-powered incentive mechanisms strenghten competition and reduce the prices of both firms and the associated profits (such a result would emerge also in the model of Raith, 2003).

Consider now the case of free entry. Firm $L$ can choose its incentive contract $k$ before entry occurs. This implies that the endogenous market structure will be characterized by a price $p_{L}(k)$ for firm $L$ which is again decreasing in $k$, and by a price $p$ for all the other firms and an associated price aggregator $P$ which satisfy optimality and free entry conditions and do not depend on $k$. Using the equilibrium expression $P_{-L}=P+g(p)-g\left(p_{L}(k)\right)$, the optimal incentive scheme for firm $L$ must solve the problem:

$$
\max _{k} D\left[p_{L}(k), P+g(p)-g\left(p_{L}(k)\right)\right]\left(p_{L}(k)-c+\frac{k}{d}\right)-\bar{w}-\frac{k^{2}}{2 d}-\frac{\gamma k^{2} \sigma^{2}}{2}
$$

whose optimality condition provides the following implicit expression:

$$
k^{*}=\frac{D\left(p_{L}, P_{-L}\right)-d\left(p_{L}-c\right) \Delta_{L L} p_{L}^{\prime}}{1+\gamma d \sigma^{2}+\Delta_{L L} p_{L}^{\prime}}
$$

where we used the equilibrium pricing condition for firm $L$ and $\Delta_{L L}=D_{2}\left(p_{L}, P_{-L}\right) g^{\prime}\left(p_{L}\right)$. Now the difference compared to the Holmostrom and Milgrom (1991) scheme is due to the positive impact on demand that derives from a price reduction induced by stronger incentive mechanisms. It is exactly the indirect impact of a price reduction on demand (due to the 
lower number of rivals) that makes it useful to adopt a larger variable compensation for the manager to enhance cost efficiency. ${ }^{13}$

We can summarize our findings as follows:

Proposition 2. Under competition in prices with endogenous entry and with moral hazard of the managers in cost-reducing activities, a firm would always gain from committing to stronger high-powered incentive schemes for its managers than the other firms.

It is important to verify that the same optimal mechanism emerges when all the other firms simultaneously choose their incentive contracts and their market strategies (given the incentive contract of firm $L$ ). In such a case, the symmetric equilibrium incentive mechanism for all the other firms ${ }^{14}$ would require the standard Holmstrom-Milgrom mechanism $\bar{k}=$ $D(p, P) /\left(1+\gamma d \sigma^{2}\right)$ because strategic considerations are absent for these firms, and the prices would satisfy the symmetric pricing condition $D(p, P)+D_{1}(p, P)(p-c+\bar{k} / d)=0$ and the free entry condition $D(p, P)(p-c+\bar{k} / d)=F$. Given this, firm $L$ would choose its contract according to the same rule as in (12), which shows that $k^{*}>\bar{k}$ again.

In case of endogenous market structures a firm has an incentive to reward more a better performance so as to reduce expected costs and increase expected sales and profits. ${ }^{15}$ Correspondingly, the effort and the expected wage must be increasing with the optimal $k$. In other words, a firm gains from paying its managers more and with more high-powered schemes under an endogenous competitive pressure: this happens to stimulate their effort and develop a comparative cost advantage over the competitors.

These results naturally lead to implications for the empirical reserach on incentive contracts (see Prendergast, 1999). A weak but positive relation between competition and incentives to promote effort has been emphasized in recent investigations by Cuñat and Guadalupe (2005) and Bloom and Van Reenen (2007). Our results suggest that the strength of the competitive entry threat in a market may crucially affect the nature of the incentive contracts:

\footnotetext{
${ }^{13}$ Similar results would emerge with straightforward extensions of the Holmstrom-Milgrom case, as with multiple tasks by the same manager, multiple agents, or payments conditional on other information correlated with effort.

${ }^{14}$ Here we are implicitly assuming that both contract and pricing decisions are taken simultaneously. If contract decisions were taken before pricing decisions, there would be an additional incentive to reduce $\bar{k}$ due to the strategic effects on equilibrium prices (see also Vives, 2008).

${ }^{15}$ Also this result can be derived from the general principle of strategic commitments because $\Pi_{13}\left(p_{L}, P_{-L}, k\right)=D_{1}\left(p_{L}, P_{-L}\right) / d<0$. Notice that the results would change if the agent's effort was affecting demand rather than costs.
} 
these should be aimed at inducing more effort when the entry threat is stronger compared to the case of markets without entry threats.

It is easy to verify that our results hold also under quantity competition and endogenous entry (because it is always convenient to promote production and reduce the total production of the rivals). However, notice that the optimal strategic contract does not replicate the best pre-commitment equilibrium (here the Stackelberg equilibrium in prices with endogenous entry), which would require the Holmstrom-Milgrom scheme with a precommitment to a lower price. ${ }^{16}$ In the presence of moral hazard, the marginal benefit of a tougher management must be balanced with the marginal cost of inducing extra effort. Nevertheless, also in this case, the optimal contract does not affect the equilibrium price index, therefore it tends to leave consumer surplus unchanged, but it increases total welfare through the positive impact on total profits (see the Appendix for a formal derivation with microfounded demand functions). As a consequence, the adoption of incentive contracts inducing extra effort is always welfare improving.

This example has shown that a principal-agent contract should adopt incentive schemes not only to encourage effort and provide risk sharing, but also to encourage the management to be tougher in the market. In the next section we will see that a similar result emerges in the presence of adverse selection.

\section{Screening contracts and adverse selection}

The purpose of this section is to characterize the optimal screening contracts for managers with private information on their productivity. ${ }^{17}$

Consider a manager exerting effort $k$ which reduces the marginal cost of production to $c-f(k)$ with $f^{\prime}(k)>0, f^{\prime \prime}(k)<0$ and $f(0)=0$. Effort and compensation $w$ determine the utility:

$$
u(w, k)=w-\theta k
$$

where $\theta$ is a productivity parameter that is private information and can take values $\theta_{1}$ or

\footnotetext{
${ }^{16}$ Under price competition, the optimal pre-commitment would require a price $p_{L}$ satisfying $D\left(p_{L}, P_{-L}\right)+$ $\left(p_{L}-c+\bar{k} / d\right)\left[D_{1}\left(p_{L}, P_{-L}\right)-\Delta_{L L}\right]=0$.

${ }^{17}$ For a good introduction to the principal-agent theory with adverse selection see Laffont and Martimort (2002). Only few papers have analyzed the optimal principal-agent contracts for firms engaged in market competition: see Martin (1993), Martimort (1996) and, more recently, Etro and Cella (2010).
} 
$\theta_{2}>\theta_{1}$ with probabilities $\nu$ and $1-\nu$. For a given contract $(w, k)$, the profits of firm $L$ are given by:

$$
\pi_{L}=D\left(p_{L}, P_{-L}\right)\left[p_{L}-(c-f(k))\right]-w-F
$$

while the profits of the other firms are given by $\pi_{i}=D\left(p_{i}, P_{-i}\right)\left(p_{i}-c\right)-F$ under the simple assumption that they do not use incentive contracts (below we briefly discuss how to relax this assumption).

It is easy to verify that in the case of a duopoly, firm $L$ would have a strategic incentive to distort downward the effort of its manager, and would choose its contracts accordingly to soften price competition. However, here we will characterize the optimal screening contract offered by firm $L$ in the presence of endogenous entry in the market.

Once a contract $(w, k)$ is decided and the manager exerts effort $k$, the endogenous market structure is characterized by the usual optimality and free entry conditions:

$$
\begin{gathered}
D\left(p_{L}, P_{-L}\right)+D_{1}\left(p_{L}, P_{-L}\right)\left[p_{L}-c+f(k)\right]=0 \\
D(p, P)+D_{1}(p, P)(p-c)=0, \quad D(p, P)(p-c)=F
\end{gathered}
$$

where $p$ and $P$ are independent from the effort of the manager, but $p_{L}(k)$ is decreasing in it. It follows that $P_{-L}(k)=P+g(p)-g\left(p_{L}(k)\right)$ is decreasing in $k$.

The optimal screening contract involves two alternatives $\left(w_{1}, k_{1}\right)$ and $\left(w_{2}, k_{2}\right)$ for managers of types $\theta_{1}$ and $\theta_{2}$. The contract must maximize expected profits under individual rationality and incentive compatibility constraints:

$$
w_{j} \geq \theta_{j} k_{j}, w_{j}-\theta_{j} k_{j} \geq w_{q}-\theta_{j} k_{q} \quad \text { with } j, q=1,2
$$

Usual arguments deliver that the binding constraints will be the individual rationality constraint for the inefficient type, $w_{2}=\theta_{2} k_{2}$, and the incentive compatibility constraint for the efficient type, $w_{1}=\theta_{1} k_{1}+\left(\theta_{2}-\theta_{1}\right) k_{2}$. Therefore, we can state the problem as follows:

$$
\begin{aligned}
& \max _{\left(k_{1}, k_{2}\right)} \nu\left[D\left(p_{L}\left(k_{1}\right), P_{-L}\left(k_{1}\right)\right)\left[p_{L}\left(k_{1}\right)-c+f\left(k_{1}\right)\right]-\theta_{1} k_{1}+\left(\theta_{2}-\theta_{1}\right) k_{2}\right]+ \\
& +(1-\nu)\left[D\left(p_{L}\left(k_{2}\right), P_{-L}\left(k_{2}\right)\right)\left[p_{L}\left(k_{2}\right)-c+f\left(k_{2}\right)\right]-\theta_{2} k_{2}\right]
\end{aligned}
$$

Defining $D(k) \equiv D\left[p_{L}(k), P+g(p)-g\left(p_{L}(k)\right)\right]$ and using the envelope theorem, we can express the first order conditions as:

$$
f^{\prime}\left(k_{1}^{*}\right) D\left(k_{1}^{*}\right)=\theta_{1}-\frac{\Delta_{L L} p_{L}^{\prime}\left(k_{1}^{*}\right) D\left(k_{1}^{*}\right)}{D_{1}\left(k_{1}^{*}\right)}
$$




$$
f^{\prime}\left(k_{2}^{*}\right) D\left(k_{2}^{*}\right)=\theta_{2}+\frac{\nu}{1-\nu}\left(\theta_{2}-\theta_{1}\right)-\frac{\Delta_{L L} p_{L}^{\prime}\left(k_{2}^{*}\right) D\left(k_{2}^{*}\right)}{D_{1}\left(k_{2}^{*}\right)}
$$

whose difference relies in the usual downward distortion of the effort of the inefficient type, which depends on the productivity difference $\left(\theta_{2}-\theta_{1}\right)$. More interestingly for our purposes, both efforts are increased through the last terms on the right hand side, which decrease the marginal cost of effort. ${ }^{18}$ Both types are required to exert more effort for strategic purposes, which reduces the price in both states of the world, with a positive impact on the expected profits. However, notice that this increases also the informational rent of the efficient type, which is simply:

$$
u\left(w_{1}, k_{1}\right)=\left(\theta_{2}-\theta_{1}\right) k_{2}
$$

In the presence of adverse selection, part of the gains in profits from a more aggressive competition must be shifted to the managers, and in particular to the efficient types of managers. Once again, the optimal contract leaves unchanged the equilibrium price index, therefore it tends to increase total welfare through an increase of the total profits with an unchanged consumer surplus (see the Appendix).

Notice that the same results hold in a more general setting. In case of a general distribution of $\theta$ on $\left[\theta_{1}, \theta_{2}\right]$ according to a cumulative distributive function $G(\theta)$ with density $g(\theta)$ and satisfying the monotone hazard rate property for which $G(\theta) / g(\theta)$ is increasing in $\theta$, the optimal contract requires effort choices with:

$$
f^{\prime}\left(k^{*}\right) D\left(k^{*}\right)=\theta+\frac{G(\theta)}{g(\theta)}-\frac{\Delta_{L L} p_{L}^{\prime}\left(k^{*}\right) D\left(k^{*}\right)}{D_{1}\left(k^{*}\right)}
$$

which leads to the same implications as above. Summing up:

Proposition 3. Under competition in prices with endogenous entry and with asymmetric information on the productivity of the managers in cost-reducing activities, a firm would always gain from screening contracts inducing extra effort for all types.

Also in this case, we would obtain the same qualitative result under competition in quantities and endogenous entry, because extra effort would induce aggressive behavior in all cases.

What happens when all firms are allowed to choose their screening contracts (that is when we have genuine competition in contracts)? This interesting issue raises more complex

\footnotetext{
${ }^{18}$ To verify that the general principle of strategic commitments applies, notice that $\Pi_{13}\left(p_{L}, P_{-L}, k\right)=$ $D_{1}\left(p_{L}, P_{-L}\right) f^{\prime}(k)<0$. The optimal effort is higher for both types when $\Delta_{L L}$ is large, that is when there is a large indirect impact of a price cut on demand (through the reduction of the number of competitors).
} 
problems, because strategic interactions between firms affect the nature of the incentive contracts and vice versa. In a duopoly, the profits depend on the efforts of both managers, and therefore the contracts of each firm affect the absolute and marginal profitability of the other firm. The downward distortion of the effort required from the inefficient managers leads the equilibrium contracts to increase the effort required from the efficient managers (above the level obtained without asymmetric information). ${ }^{19}$ However, when possible, a firm would still like to commit to contracts that require lower efforts with the purpose of softening competition. Such a motivation would disappear in case of endogenous entry, because lower effort would simply attract new competitors and reduce profitability. Again, these results could lead to interesting empirical investigations on the impact of entry threats on the nature of the incentive contracts in different markets.

As we have seen, a vertical principal-agent structure can be used to promote aggressive competition and increase its profits in a market characterized by free entry. In the next section we will see that even in the absence of incentive contracts, the same purpose can be achieved through vertical separation and appropriate franchising contracts.

\section{Vertical contracts and hold up}

Following Bonanno and Vickers (1988) and Rey and Stiglitz (1995), let us reconsider our model of price competition introducing the possibility for a firm to produce the good, but to delegate its distribution (for the final consumers) to a separate firm by means of a vertical contract of franchising.

Assume that firm $L$ separates vertically: an upstream firm produces the good and delegates its distribution on the market to a downstream firm through a two-part tariff implying a fixed fee $\Upsilon$ and a wholesale price $w$ for the good. The downstream firm sells this same good at the price $p_{D}$ to maximize net profits:

$$
\pi_{D}=\left(p_{D}-w\right) D\left(p_{D}, P_{-D}\right)-\Upsilon
$$

while the other firms remain vertically integrated and bear a marginal cost $c$ and a fixed cost $F$. The upstream firm produces its good with the same technology and chooses the franchising contract with the downstream firm, that is the pair $(w, \Upsilon)$ that maximizes net

\footnotetext{
${ }^{19}$ In other words, the "no distortion on the top" property fails for equilibrium strategic reasons. See Etro and Cella (2010) for an investigation of this form of competition in contracts.
} 
profits:

$$
\pi_{L}=(w-c) D\left(p_{D}, P_{-D}\right)+\Upsilon-F
$$

It is always optimal to choose $w$ such that the profits of the downstream firm are maximized, and the fee that fully expropriates these profits. In an influential work, Bonanno and Vickers (1988) have shown that when $n=2$ it is optimal to choose a high wholesale price $w>c$ to soften price competition, and increase prices and profits. When entry in the market is endogenous, however, the firm cannot operate in this way, because high wholesale prices would put the downstream firm out of business. Nevertheless, the firm can still gain from delegating pricing decisions to the downstream retailer, but with an optimal contract which is now radically different.

As in the previous applications, given the pair $(w, \Upsilon)$, the endogenous market structure is characterized by a price of the downstream firm $p_{D}(w)$ which depends on $w$, and is now increasing in it, and by a price for the other firms $p$ and an endogenous value for the price aggregator $P$ that are both independent from $w$, with $P_{-D}=P+g(p)-g\left(p_{D}(w)\right)$. The optimal contract solves the problem:

$$
\begin{aligned}
\max _{(w, \Upsilon)} \pi_{L} & =(w-c) D\left[p_{D}(w), P_{-D}\right]+\Upsilon-F \\
\text { s.v. } & : \quad \pi_{D}=\left[p_{D}(w)-w\right] D\left[p_{D}(w), P_{-D}\right]-\Upsilon \geq 0
\end{aligned}
$$

Since the constraint is always binding, we can substitute this and the equilibrium definition of $P_{-D}$ to rewrite the problem as:

$$
\max _{w} \pi_{L}=\left[p_{D}(w)-c\right] D\left[p_{D}(w), P+g(p)-g\left(p_{D}(w)\right)\right]-F
$$

The solution requires a wholesale price for the retailer smaller than the marginal cost and implicitly given by:

$$
w^{*}(c)=c-\frac{\left(p_{D}-c\right) \Delta_{D D}}{\left[-D_{1}\left(p_{D}, P_{-D}\right)\right]}<c
$$

where we combined the optimality condition with the equilibrium pricing condition for the downstream firm and we defined $\Delta_{D D}=D_{2}\left(p_{D}, P_{-D}\right) g^{\prime}\left(p_{D}\right)>0$. This wholesale price generates a lower equilibrium price and a higher output for the downstream retailer than for the other firms, and provides positive profits for the upstream firm. ${ }^{20}$ Summing up:

\footnotetext{
${ }^{20}$ To verify that the general principle of strategic commitments applies, define $k=c-w$ as the wholesale discount, and $\Pi\left(p_{D}, P_{-D}, k\right)=\left(p_{D}-c+k\right) D\left(p_{D}, P_{-D}\right)$ as the gross profit of the delegated firm. Then, we have $\Pi_{13}\left(p_{D}, P_{-D}, k\right)=D_{1}\left(p_{L}, P_{-L}\right)<0$. Once again, notice that the wholesale discount is larger when $\Delta_{D D}$ is large, that is when there is a large indirect impact of a price cut on demand (through the reduction of the number of competitors).
} 
Proposition 4. Under competition in prices with endogenous entry, a firm would always gain from separating vertically and adopting a franchising contract toward the downstream firms with a two-part tariff and a wholesale price below the marginal cost.

Contrary to the result of Bonanno and Vickers (1988), as long as entry is endogenous and two-part tariffs are available, it is optimal to delegate distribution to a retailer with a francise fee contract involving a wholesale price below marginal cost, because this induces the retailer to price aggressively in the market, conquer a larger market share and retain positive profits in spite of free entry. Notice that the same result could be reached with a resale price maintenance or with a mechanism of quantity forcing. ${ }^{21}$ It is immediate to verify that the same qualitative result holds also under quantity competition (once again, it is convenient to induce higher production of the retailer to reduce total production of the rivals), therefore strategic vertical separation with wholesale prices below cost is always optimal in case of endogenous market structures.

\subsection{Antitrust implications}

The theory of vertical separation under interbrand (price) competition has been used to motivate anti-competitive behavior through vertical restraints. ${ }^{22}$ However, our result shows that there is no ground for conjecturing any anti-competitive behavior in markets open to entry because two-part tariffs are used to reduce the final prices: in the Appendix we also show that these vertical contracts do not affect consumer surplus, but they increase total profits and welfare. It is important to remark that such an aggressive strategy could not emerge under linear pricing (without fixed fee), because the upstream firm would be unable to induce a low final price and extract profits at the same time: vertical separation is effective only with non-linear pricing when entry is endogenous.

Our result on the optimal two-part tariff can be used also to revisit some of the insights of the antitrust literature on exclusive dealing. ${ }^{23}$ Suppose that upstream firms produce a

\footnotetext{
${ }^{21}$ The same mechanism of resale price maintenance is analyzed by Shaffer (1991) with an exogenous number of firms and requires the upstream firm to impose the optimal price on the downstream firm while extracting all its profits with an appropriate wholesale price. The mechanism of quantity forcing requires an appropriate two-part tariff to induce the appropriate price and extract the full surplus from the retailer. I am thankful to Ryoko Oki for pointing this out.

${ }^{22}$ See Motta (2004) for an extensive treatment of this model with exogenous entry. On applications of the endogenous market structure approach to antitrust issues see Etro (2007).

${ }^{23}$ The recent literature on exclusive dealing when buyers are competing distributors is entirely confined
} 
homogenous good at constant marginal cost $c$ and sell it to a downstream sector. The downstream sector uses the good as an input to produce differentiated final goods and is characterized by positive fixed costs and endogenous entry. Price competition in both markets leads to marginal cost pricing for the input $(w=c)$ and zero profits for all the firms. However, an upstream firm could offer an exclusive dealing contract to a downstream firm, and then use the same two-part tariff as above to induce aggressive pricing and extract a positive profit. Actually, any downstream firm would be available to sign such a contract for a negligible fee, because the alternative would be zero profits. Most important, this would be possible even if the upstream firm was relatively inefficient, say with a marginal $\operatorname{cost} c_{I}$ slightly higher than the marginal cost of the other upstream firms, say $c_{E} \cdot{ }^{24}$ Again, such an exclusive dealing contract would strengthen price competition without predatory purposes (and, again, it would not work in case of simple linear input prices). ${ }^{25}$

\subsection{Specific investments and incomplete contracts}

In the rest of this section we examine a form of inefficiency that often emerges in the presence of vertical contracts. Until now (since we did not introduce any transaction costs) the optimal vertical contract was able to replicate the best reachable equilibrium, that is the Stackelberg equilibrium in prices with endogenous entry. However, as pointed out in a general framework by Grossman and Hart (1986) and Hart and Moore (1990), contractual incompleteness can undermine the optimality of vertical separation when the two firms undertake relation-specific and unverifiable investments. ${ }^{26}$ In what follows, we examine this possibility in the tradition of the property rights theory.

Suppose that, in a preliminary stage, the upstream firm can invest $\mathbf{e}$ to reduce the marginal to the case of an exogenous number of distributors - see Fumagalli and Motta (2006) corrected by Wright (2009), and especially Abito and Wright (2008). I am thankful to a referee for pointing out this application, and to Ryoko Oki for long discussions on exclusive dealing with endogenous entry.

${ }^{24} \mathrm{As}$ long as $w^{*}\left(c_{I}\right)<c_{E}$, the exclusive dealing contract induces aggressive pricing and can be profitable. If this is the case, the upstream firm gains from extending the same exclusive dealing contract to other downstream firms. One could then investigate under which conditions an endogenous number of exclusive dealing contracts can deter entry of a more efficient upstream producer. We leave this important issue for future research.

${ }^{25}$ In general, this suggests that, at least under linear pricing and endogenous entry in the downstream market, exclusive dealing cannot have a strategic (or predatory) purpose, but can only have an efficiency rationale. This is in line with the results of the Chicago School on exclusive dealing.

${ }^{26}$ See also Segal and Whinston (2000). 
cost at the level $c(\mathbf{e})$, and the downstream firm can invests $\mathbf{i}$ to increase demand at the level $D\left(p_{D}, P_{-D}, \mathbf{i}\right)$, with $c(0) \equiv c, c_{\mathbf{e}}<0$ and $c_{\mathbf{e e}}>0$ and with $D(p, P, 0) \equiv D(p, P), D_{\mathbf{i}}>0$ and $D_{\mathrm{ii}}<0$.

In case of vertical separation, the market equilibrium is characterized as above, with a wholesale price $w^{*}(c(\mathbf{e}))$. As noticed, all the surplus goes to the upstream firm and nothing to the downstream firm. With such an expectation, the downstream firm tends to underinvest ex ante, which in turn reduces the investment of the upstream firm as well. More precisely, we have the following equilibrium investments: ${ }^{27}$

$$
\begin{aligned}
\mathbf{i}^{S} & =0 \\
\left|c_{\mathbf{e}}\left(\mathbf{e}^{S}\right) D\left(p_{D}, P_{-D}, 0\right)\right| & =1
\end{aligned}
$$

This is the classic "hold up" problem (Klein et al., 1978; Williamson, 1979) which limits the benefits of vertical separation. Both firms could gain from committing to the higher first-best investment (which maximizes their joint surplus), that is:

$$
\left[p_{D}-c\left(\mathbf{e}^{*}\right)\right] D_{\mathbf{i}}\left(p_{D}, P_{-D}, \mathbf{i}^{*}\right)=1 \text { and }\left|c_{\mathbf{e}}\left(\mathbf{e}^{*}\right) D\left(p_{D}, P_{-D}, \mathbf{i}^{*}\right)\right|=1
$$

but the impossibility of writing (or enforcing) contracts on the division of the surplus leads to inefficient underinvestment.

In case of vertical integration, the integrated firm $L$ competes simultaneously with the other integrated firms, losing the commitment power associated with the franchising contract. In equilibrium, firm $L$ chooses a price $p_{L}=p(\mathbf{e}, \mathbf{i})$ that satisfies the standard optimality condition:

$$
D\left(p_{L}, P_{-L}, \mathbf{i}\right)+D_{1}\left(p_{L}, P_{-L}, \mathbf{i}\right)\left[p_{L}-c(\mathbf{e})\right]=0
$$

and is decreasing in e and increasing in i. As usual, the endogenous market structure is characterized by a price for the other firms $p$ and an endogenous value for the price aggregator $P$ that are both independent from $p(\mathbf{e}, \mathbf{i})$, with $P_{-L}=P+g(p)-g\left(p_{L}\right)$ depending on the two investments. Ex ante, these investments are chosen by the integrated firm to solve the problem:

$$
\max _{\mathbf{e}, \mathbf{i}} D\left(p_{L}, P+g(p)-g(p(\mathbf{e}, \mathbf{i})), \mathbf{i}\right)\left[p_{L}-c(\mathbf{e})\right]-F-\mathbf{e}-\mathbf{i}
$$

\footnotetext{
${ }^{27}$ Notice that $d \mathbf{e} / d \mathbf{i}=-c_{\mathbf{e}} D_{\mathbf{i}} / c_{\mathbf{e e}} D>0$ under our assumptions. The suboptimality of both investments follows from the fact that they are complements in the sense of Hart (1995): the cross derivative of total surplus with respect to $\mathbf{e}$ and $\mathbf{i}$ is positive.
} 
which leads to the following optimality conditions:

$$
\begin{aligned}
{\left[p\left(\mathbf{e}^{I}, \mathbf{i}^{I}\right)-c\left(\mathbf{e}^{I}\right)\right]\left(D_{\mathbf{i}}\left(\cdot, \mathbf{i}^{I}\right)-\Delta_{L L} p_{\mathbf{i}}\left(\mathbf{e}^{I}, \mathbf{i}^{I}\right)\right) } & =1 \\
\left|c_{\mathbf{e}}\left(\mathbf{e}^{I}\right) D\left(\cdot, \mathbf{i}^{I}\right)+\left(p\left(\mathbf{e}^{I}, \mathbf{i}^{I}\right)-c\left(\mathbf{e}^{I}\right)\right) \Delta_{L L} p_{\mathbf{e}}\left(\mathbf{e}^{I}, \mathbf{i}^{I}\right)\right| & =1
\end{aligned}
$$

The two investments are used beyond their direct benefits. Once again, the strategic purpose is to commit to a low price against the rivals, which requires extra investment in e and less investment in i. However, since these investments are costly, they do not allow the integrated firm to replicate the best precommitment equilibrium. In conclusion, strategic reasons lead the integrated firm to distort investment to reduce the price.

At this point one can compare the relative merits of vertical separation and vertical integration in markets whose structure is endogenous. Vertical separation allows one to implement the optimal aggressive pricing strategy through the franchising contract, but leads to suboptimal investments (especially for the downstream firm) in relation-specific activities. Vertical integration allows one to fully internalize the investment strategies, but requires costly distortions from the optimal investments to obtain a strategic advantage in the market. Of course, the trade-off between these benefits and costs determines whether vertical contracts are optimal. Nevertheless, even when these contracts remain optimal, this simple example shows that hold up problems (and not only informational asymmetries) can create distortions that limit the effectiveness of strategic contracts.

There are many other contractual arrangements that affect market competition. Some of them, just as the vertical contracts examined in this section, are also relevant for the antitrust analysis of dominant firms. In the next section we focus on a well known example of horizontal contracts, that is contracts affecting competition between firms selling to the same buyers.

\section{Tying contracts}

Tying involves a contractual agreement whereby a seller gives buyers access to a product only if the buyers agree to purchase another product as well. In an influential article, Whinston (1990) has shown that when a monopolist in a primary market is active also in a secondary market characterized by a Bertrand duopoly, tying of the two goods can only be used for entry deterrence purposes, because by itself it can only strengthen competition and reduce profits in both markets. However, this result, which has been at the basis of the modern 
antitrust approach to tying, ${ }^{28}$ breaks down when the structure of the secondary market is endogenous. ${ }^{29}$

To verify this, let us follow Whinston (1990) and consider two markets without any complementarities on the supply or demand side. Imagine for simplicity that the primary market is a monopolistic one characterized by zero costs of production and a constant demand $D_{M}$ at the price $v$, which corresponds to the valuation of the primary good alone. The secondary market is characterized by product differentiation and price competition as in our usual set-up. In the absence of tying, the gross profits of the monopolist, which is active also in the secondary market as firm $M$, are the sum of the profits in both markets:

$$
\pi_{M}=v D_{M}+\left(p_{M}-c\right) D\left(p_{M}, P_{-M}\right)-F
$$

while profits for any other firm $i$ derive from the secondary market only:

$$
\pi_{i}=\left(p_{i}-c\right) D\left(p_{i}, P_{-i}\right)-F
$$

Under tying, the demand for the monopolistic good is constrained by the demand for the other good, which is assumed to be lower than $D_{M}$ (to focus on the interesting case). The bundle price $p_{M B}$ can be decomposed as $p_{M B}=v+p_{M}$ where $p_{M}$ can be now interpreted as an implicit price of the secondary good produced by the monopolist. In such a case, the profits for the monopolist become:

$$
\pi_{M B}=\left(p_{M B}-c\right) D\left(p_{M B}-v, P_{-M}\right)-F=\left(p_{M}+v-c\right) D\left(p_{M}, P_{-M}\right)-F
$$

The other firms have the same objective function as before.

First of all, let us summarize the results of Whinston (1990) for the case of a single potential rival in the secondary market. A commitment to bundle strengthens competition in the secondary market. Therefore, in case of entry of the single rival, it reduces the profits of the monopolist in both markets. However, in case of entry deterrence, the monopolist remains alone and can choose the monopolistic price of the bundle: even if this delivers lower profits than the uncostrained monopolistic prices, under weak conditions it is a profitable

\footnotetext{
${ }^{28}$ For recent developments always in a duopolistic set up, see Nalebuff (2004) and Peitz (2008).

${ }^{29}$ An earlier version of this idea (presented in Etro, 2007) based the optimality of tying on network effects or cost sinergies. I am grateful to Jan Vandekerckhove, whose numerical simulations led me to realize the importance of the size of the demand for the stand alone product (relative to the demand for the bundle) for the general optimality of tying contracts.
} 
strategy and reduces consumer utility. This is a classic example of predatory strategy (aimed at inducing exit and establishing a monopoly), forbidden in most antitrust regulations.

Let us move now to the general case of endogenous market structures, assuming that the fixed cost is low enough to allow entry of multiple rivals in the secondary market. Without tying, endogenous entry exhausts all the profitable opportunities in the secondary market, and the monopolist enjoys equilibrium profits from the primary market only:

$$
\pi_{M}=v D_{M}
$$

Consider tying now. In Bertrand equilibrium the monopolist chooses the bundle price $p_{B M}=$ $p_{M}+v$ satisfying:

$$
\left(p_{M}+v-c\right) D_{1}\left(p_{M}, P_{-M}\right)+D\left(p_{M}, P_{-M}\right)=0
$$

while each one of the other firms chooses $p$ satisfying the first order and free entry conditions:

$$
(p-c) D_{1}(p, P)+D(p, P)=0 \quad \text { and } \quad(p-c) D(p, P)=F
$$

so that the profits of the tying monopolist become $\pi_{M B}=\left(p_{M}+v-c\right) D\left(p_{M}, P_{-M}\right)-F$. As usual, $p$ and $P$ do not depend on $v$ and on the tying strategy, while $p_{M}(v)$ has to be decreasing in $v .^{30}$ Therefore, the price of the bundle $p_{B M}=p_{M}(v)+v$ increases less than proportionally with $v$, and the monopolist offers the bundle with a discount on the secondary good compared to its competitors. Clearly, tying is optimal if $\pi_{M B}>\pi_{M}$, that is, if:

$$
\left[p_{M}(v)-c\right] D\left[p_{M}(v), P_{M}\right]-F>v\left\{D_{M}-D\left[p_{M}(v), P_{M}\right]\right\}
$$

whose left hand side is the gain in profits in the competitive market and whose right hand side is the loss in profits in the monopolistic market: as long as the demand in the primary market, given by the exogenous parameter $D_{M}$, is close enough to the demand for the bundled $\operatorname{good} D\left[p_{M}(v), P_{M}\right]$, this inequality is automatically satisfied. For instance, consider the case (microfounded in the Appendix) of isoelastic demand $D\left(p_{i}, P_{-i}\right)=E p_{i}^{-\theta} / \sum_{j=1}^{n} p_{j}^{1-\theta}$ with $E$ demand size and $\theta$ elasticity of substitution. The equilibrium price of the secondary goods is:

$$
p=\frac{c \theta E}{(\theta-1)(E-F)}
$$

\footnotetext{
${ }^{30}$ In particular we have:

$$
p_{M}^{\prime}(v)=\frac{-D_{1}\left[p_{M}, P+g(p)-g\left(p_{M}\right)\right]}{\Delta}<0
$$

where $\Delta \equiv 2 D_{1}+\left(p_{M}+v-c\right)\left[D_{11}-g^{\prime}\left(p_{M}\right) D_{12}\right]-g^{\prime}\left(p_{M}\right) D_{2}<0$ by the stability of the equilibrium system.
} 
and the equilibrium price of the bundle satisfies:

$$
p_{M}(v)<p \text { and } p_{M}(v)>\frac{(c-v) \theta E}{(\theta-1)(E-F)}
$$

The condition for the profitability of tying can be solved for:

$$
p_{M}(v)>\frac{(c-v) \theta E}{(\theta-1)\left(E-F-v D_{M}\right)}
$$

which is always satisfied for $D_{M}$ small enough.

Summing up our general insights, we have:

Proposition 5. When a monopolist in a primary market is active in a secondary market under competition in prices with endogenous entry, the monopolist gains from tying its two goods (without fully deterring entry) as long as the demand for the bundle is close enough to the demand of the monopolistic product.

It should be clear that tying does not allow the monopolist to replicate the best equilibrium (which would require monopolistic pricing in the primary market and price leadership in the secondary one). The inefficiency here is due to the fact that tying is a discrete strategy that generates an advantage from the pre-commitment on the bundle price, but also a cost from the rigidity of the price strategy in the two separate markets. ${ }^{31}$ However, it is an example of a contractual restriction on consumers that can improve profits while reducing prices. This is possible because of the inefficient pricing emerging without tying, which allows the monopolist to reduce the bundle price and still be able to gain market shares and profits. Not surprisingly, the same outcome emerges under competition in quantities.

\subsection{Antitrust implications}

We have shown that when 1) the secondary market is characterized by differentiated goods and an endogenous market structure with space for multiple firms, and 2) the demand for the bundled good is close enough to the demand of the primary product, tying is a profitable device to reduce prices without fully deterring entry in the secondary market (which was

\footnotetext{
${ }^{31}$ Loosely speaking, one cannot choose the optimal degree of tying, but can only choose yes or no. For the same reason (the discreteness of the choice) we cannot employ the general principle of strategic commitments of Etro (2006). However, $\partial \pi_{M B} / \partial p_{M}-\partial \pi_{M} / \partial p_{M}=v D_{1}<0$, therefore tying makes the monopolist tough. This implies that the monopolist is led to reduce the effective price in the secondary market by choosing a low price of the bundle.
} 
impossible in case of market power in the secondary market as in Whinston, 1990). It is important to remark that, with endogenous entry tying does not have a predatory purpose as assumed by the leverage theory of tied good sales, even if it tends to strengthen competition and to reduce the number of competitors in the secondary market: in the case of a single rival, tying made it possible to establish a monopoly in both markets able to increase the implicit price of the secondary good, but endogenous entry makes this impossible and actually leads to a reduction of the implicit price of the secondary good.

On the other side, our result rejects also the single-monopoly profit theorem of the Chicago school, for which a monopolist in one market cannot use tying to leverage market power in another market where entry is free: as we have seen, a monopolist can do that, because tying can create larger gains in the secondary market than losses in the primary one. Again, this is possible because of the inefficient pricing emerging in the free entry equilibrium.

As in the case of vertical restraints analyzed in the previous section, the endogenous market structures approach can also be seen as a generalization of the Chicago and postChicago approaches. When the fixed cost tends to zero, the price of the untied good tends to the marginal cost in the secondary sector and there is no strategic role for tying: this case reproduces perfect competition and the single-monopoly profit theorem. When the fixed cost is large enough, there is space for at most a single rival in the secondary market, and tying can be used for predatory purposes: in this case the leverage theory of tied good sales holds.

For (more likely) intermediate levels of the fixed costs, our result supports the spirit of the Chicago School through a game theoretic analysis similar in spirit to the post-Chicago approach: tying tends to be welfare-improving because it can induce a reduction of prices and an increase of profits. In the Appendix we analyze microfounded demand functions (as in the isoelastic example above) and show that tying does not affect consumer surplus in the secondary market. Since consumer surplus in the primary market is zero with and without tying (because of perfect price discrimination), it follows that: under endogenous entry in the secondary market, when tying is adopted, consumer surplus does not change but total profits and welfare increase.

Elsewhere (Etro, 2007, 2009) we have applied this theoretical result to a famous antitrust investigation, the European one on Microsoft, concerning the tying of the operating system Windows with software applications (Windows MediaPlayer in the first case and Internet Explorer in a second investigation). The endogeneity of entry in the markets for media players and especially for browsers (think of the rapid expansion of Firefox or the entry 
of Chrome), the possibility of multi-homing (using multiple secondary products, especially different media players) and the lack of demand for the primary product (operating systems) without the secondary ones, suggest that the conditions for the optimality of tying without predatory purposes were satisfied: therefore the tying strategies adopted by Microsoft were not anticompetitive. Further applications of the endogenous market structure approach in the analysis of exclusionary abuses are discussed in Etro and Kokkoris (2010).

\subsection{Vertical mergers}

A similar idea could be applied to analyze vertical mergers - as far as we know, the literature on vertical mergers (between a subset of firms) is entirely confined to the case of an exogenous number of firms in both the upstream and downstream sectors (Salinger, 1988; Ordover et al., 1990; Gaudet and van Long, 1996; Hackner, 2003). ${ }^{32}$

Consider an upstream monopolist selling an input to a downstream sector characterized by price competition, product differentiation and endogenous entry: a merger between the upstream firm and a downstream firm would have the traditional effect of eliminating the double marginalization for the merged firms, but it would also have the additional effect of inducing aggressive retail pricing so as to extract positive profits from the downstream market. Such an application could be exploited to examine the impact of the merger on the equilibrium prices of the input and of the final good, and it could be extended to take into account other upstream firms: while such an analysis is beyond our scope, further investigations in this direction could be fruitful.

\section{Conclusion}

In this paper we have characterized a number of optimal strategic contracts for firms active in markets with endogenous structures. Traditional results on sale incentives, managerial schemes, screening contracts, franchising, exclusive dealing and tying contracts radically change when firms compete in prices but entry in the market is endogenous. A side effect of our analysis is that the traditional ambiguity of a wide literature on strategic contracts vanishes when these are evaluated in markets with endogenous structures: in such a case, the nature of the optimal contracts does not depend on the mode of competition, but only

\footnotetext{
${ }^{32} \mathrm{I}$ am grateful to a referee for pointing out this field of applications.
} 
on their impact on endogenous entry decisions.

We have been dealing with contracts between the firm and its managers (incentive contracts) and between the firm and its customers (vertical contracts and tying), but other applications concern other stakeholders. ${ }^{33}$ For instance, in Etro (2010) I have looked at contracts between different shareholders to characterize the optimal debt contracts for a firm competiting in a market with endogenous entry. Also in that case, traditional results change and, under competition in prices with endogenous entry and cost uncertainty, the equity holders of a firm always gain from adopting debt contracts with the purpose of committing to aggressive strategies. Further theoretical research could investigate other contractual arrangements under different contractual problems (for instance renegotiation or corruption).

Finally, our results could be used to re-evaluate the empirical analysis on the relation between competition and strategic contracts. We have emphasized the impact of the entry threats on the nature of the optimal contracts: one should expect the emergence of sale incentives, high-powered incentive mechanisms and bonuses for the managers of firms facing strong entry threats and less for firms without such a threat. Further research could fruitfully focus on the impact of entry pressure on contractual arrangements.

\section{Appendix: Generalizations and welfare.}

To generalize the implications of our approach, let us consider $n$ differentiated goods produced by different firms. The consumption of each good $x_{i}$ with $i=1,2, \ldots, n$ contributes to create the following utility for a representative agent:

$$
U=\Psi\left(\sum_{j=1}^{n} u\left(x_{j}\right)\right)
$$

where $\Psi(\cdot)$ and the subutilities $u(\cdot)$ are increasing and concave functions. Maximization under a standard budget constraint with income $E$, such that $\sum_{j=1}^{n} x_{j} p_{j}=E$ delivers an inverse demand for good $i$ as $p_{i}=p\left[x_{i}, \sum_{j=1}^{n} u\left(x_{j}\right)\right]$ decreasing in the quantity of each product, which implies substitutability between goods. For instance, isoelastic preferences à la Dixit-Stiglitz generate an inverse demand nested in the above function.

\footnotetext{
${ }^{33}$ Similar results emerge in the analysis of strategic policy for firms active in foreign markets with endogenous structures: under endogenous entry it is always optimal to implement policies that induce an aggressive behavior of the domestic firms abroad. See Etro $(2009,2011)$ for a review of strategic macroeconomic policies.
} 
From the utility maximization problem, one can also obtain the direct demand for firm $i$ as depending on its price $p_{i}$ and on the price index $\bar{P}=f\left[\sum_{j=1}^{n} g\left(p_{j}\right)\right]$, for some positive functions $f(\cdot)$ and $g(p)$ with $g^{\prime}(p)<0$ such that $\sum_{j=1}^{n} x_{j} \bar{P}=E$ : notice that the minimization of this price index is by definition equivalent to the maximization of welfare. Equivalently, demand can be expressed as $D_{i}=D\left(p_{i}, P_{-i}\right)$ with $D_{1}<0, D_{2}<0$, where the price aggregator $P_{-i}=$ $\sum_{j=1, j \neq i}^{n} g\left(p_{j}\right)$ depends on all the other prices, as we did in the main text. Substitutability between goods is guaranteed by the fact that the cross derivatives $\partial D_{i} / \partial p_{j} \equiv \Delta_{i j}$ are always positive: $\Delta_{i j}=D_{2} g^{\prime}\left(p_{j}\right)>0$ for any $i$ and $j$. As an example, consider isoelastic preferences $\grave{a}$ la DixitStiglitz as:

$$
U=\left[\sum_{j=1}^{n} x_{j}^{\frac{\theta-1}{\theta}}\right]^{\frac{\theta}{\theta-1}}
$$

with $\theta$ elasticity of substitution. These preferences generate the inverse demand functions $p_{i}=$ $x_{i}^{-1 / \theta} E / \sum_{j=1}^{n} x_{j}^{1-1 / \theta}$ and the direct demand functions:

$$
D\left(p_{i}, P_{-i}\right)=\frac{E p_{i}^{-\theta}}{\sum_{j=1}^{n} p_{j}^{1-\theta}}
$$

where the well-known price index is $\bar{P}=\left[\sum_{j=1}^{n} p_{j}^{1-\theta}\right]^{1 /(1-\theta)}$, and welfare is decreasing in it.

Each firm bears a fixed cost of entry $F>0$ and produces at a variable cost $C(\cdot)$ which is increasing in output. Given this description of the technological conditions and our microfoundation of the demand side, one can express the profits of each firm in terms of the quantity strategies $x_{j}$ or of price strategies $p_{j}$, and investigate competition in quantities or in prices with (or without) endogenous entry. However, in our baseline model, we allow a single firm, say firm $L$, to adopt contractual arrangements with its partners (managers, retailers, customers, employers,..) that may affect its own profitability. For simplicity, let us summarize these agreements with a single parameter $k \geq 0$ where $k=0$ is equivalent to no agreement. Most contracts affect cost efficiency, as for the incentive contracts for the managers, but other contracts may affect the relevant objective function in different ways (as for sale-based incentives, vertical separation or tying contracts). Therefore, we will adopt a very general specification in which $k$ can affect demand or costs in an unspecified way. The timing of our main models is the following:

Stage 1: firm $L$ adopts a contractual arrangement $k$ to maximize its expected profits.

Stage 2: entry of other firms occurs until expected profits are non-negative.

Stage 3: all firms $j=1,2, \ldots, L, \ldots, n$ choose simultaneously their market strategy.

Finally, let us assume that the fixed costs are low enough or product differentiation is deep 
enough that entry of other firms is profitable in equilibrium. The subgame perfect equilibrium is characterized by a contractual arrangement $k$, a number of entrants $n$, and the associated strategies $x_{j}$ under quantity competition or $p_{j}$ under price competition. Given this, consumer surplus is associated with the resulting utility $U$, and total welfare is defined as the sum of consumer surplus and total profits. Given this model, we can prove the following general result: ${ }^{34}$

NEUTRALITY THEOREM. Under endogenous entry, the consumer surplus and the strategies of the entrants are independent from any strategic contract signed by a firm.

Proof. Consider competition in quantities first. The profit of firm $j \neq L$ can be written as:

$$
\pi_{i}=p\left[x_{i}, \sum_{j=1}^{n} u\left(x_{j}\right)\right] x_{i}-C\left(x_{i}\right)-F
$$

The profit of firm $L$ is analogous, but can be affected by the contractual arrangements summarized by $k$ :

$$
\pi_{L}=p\left[x_{L}, \sum_{j=1}^{n} u\left(x_{j}\right), k\right] x_{L}-C\left(x_{L}, k\right)-F
$$

At stage 3, all strategies must maximize profits, which delivers the following equilibrium conditions for the entrants and firm $L$ :

$$
\begin{aligned}
p(x, \mu)+p_{1}(x, \mu) x & =C^{\prime}(x) \\
p\left(x_{L}, \mu, k\right)+p_{1}\left(x_{L}, \mu, k\right) x_{L} & =C^{\prime}\left(x_{L}, k\right)
\end{aligned}
$$

where $\mu=(n-1) u(x)+u\left(x_{L}\right)$. At stage 2 , the number of firms is determined by the zero profit condition:

$$
p(x, \mu) x-C(x)=F
$$

These conditions determine $x$ and $\mu$ independently from $k$. Therefore, consumer surplus is $U=$ $\Psi(\mu)$, which is also independent from $k$. At stage 1 , firm $L$ can optimally choose $k$ without affecting $x, \mu$ and $U$.

Consider price competition now. The assumed preferences generate a direct demand for each good depending on its price and on the price index $\bar{P}=f\left[\sum_{j=1}^{n} g\left(p_{j}\right)\right]=f\left[P_{-i}+g\left(p_{i}\right)\right]$, whose minimization is equivalent to the maximization of utility. Without loss of generality, we can reexpress demand for a firm in terms of its price and of an aggregator of the other prices $P_{-i}=$

\footnotetext{
${ }^{34}$ Further investigations on this neutrality result have been independently developed by the interesting work of Anderson et al. (2010).
} 
$\sum_{j=1, j \neq i}^{n} g\left(p_{j}\right)$. Adopting the latter convention, the profit of firm $j \neq L$ can be written as:

$$
\pi_{i}=p_{i} D\left(p_{i}, P_{-i}\right)-C\left[D\left(p_{i}, P_{-i}\right)\right]-F
$$

The profit of firm $L$ is analogous, but can be affected by the contractual arrangements summarized by $k$ :

$$
\pi_{L}=p_{i} D\left(p_{i}, P_{-i}, k\right)-C\left[D\left(p_{i}, P_{-i}, k\right), k\right]-F
$$

At stage 3, all strategies must maximize profits, which delivers the following equilibrium conditions for the entrants and firm $L$ :

$$
\begin{aligned}
D(p, P)+p D_{1}(p, P) & =C^{\prime}[D(p, P)] D_{1}(p, P) \\
D\left(p_{L}, P_{-L}, k\right)+p_{L} D_{1}\left(p_{L}, P_{-L}, k\right) & =C^{\prime}\left[D\left(p_{L}, P_{-L}, k\right), k\right] D_{1}\left(p_{L}, P_{-L}, k\right)
\end{aligned}
$$

where $P=(n-2) g(p)+g\left(p_{L}\right)$ and $P_{-L}=(n-1) g(p)$. At stage 2, the number of firms is determined by the zero profit condition:

$$
p D(p, P)-C[D(p, P)]=F
$$

These conditions determine $p$ and $P$ independently from $k$. Therefore, also the price index $\bar{P}=$ $P+g(p)$ is independent from $k$, which implies that consumer surplus $U$ is independent as well. At stage 1, firm $L$ can optimally choose $k$ without affecting $p, P$ and $\bar{P}$.

This theorem shows that, even if the contract chosen by firm $L$ can affect the profitability and the equilibrium strategy of the same firm (which can affect entry of competitors as well), ultimately it is neutral toward the strategies adopted by the other firms and the utility of consumers. Profit maximization and endogenous entry determine the strategies of the entrants and, through this, the relevant measure of welfare for the consumers. When the contract induces an aggressive strategy, for instance a larger production or a lower price, this does not affect the strategies chosen by the competitors but has to restrict entry (and vice versa for a contract inducing an accommodating strategy). For instance, under competition in quantities the total production remains the same even if the contractual arrangement changes the production of the firm adopting it, and under competition in prices a properly defined price index remains unchanged even if there is a change in the price of the firm adopting the contractual arrangement. An immediate corollary of the above theorem is the following:

COROLLARY. Whenever the contractual arrangement is optimally chosen in equilibrium, total welfare must be (weakly) increased. 
The reason is that, whenever a contract is adopted by firm $L$, it must (weakly) increase its profits without affecting consumer surplus and leaving zero profits to all the entrants. This is what happened in our models when the demand function was microfounded as above.

A related investigation by Etro (2006) on a more general (but not microfounded) class of games with endogenous entry has provided a more precise characterization of the equilibria: there is always a strategic incentive to adopt a preliminary commitment which increases the marginal profitability of a higher production, or decreases the marginal profitability of a higher price $-\Pi_{13}\left(p_{L}, P_{-L}, k\right)<0$ in the main text. As a consequence, under both quantity and price competition, it is optimal to adopt contractual commitments finalized to an aggressive pricing behavior in the market: sale incentives, high-powered incentive contracts, screening contracts inducing extra effort, franchising contracts with extra sales for the retailers and tying contracts. Moreover, as a consequence of our previous results for microfounded demand functions, the unilateral adoption of the optimal contracts does not affect consumer surplus and (weakly) increases total welfare.

\section{References}

Abito, Jose Miguel and Julian Wright. 2008. "Exclusive Dealing with Imperfect Downstream Competition." International Journal of Industrial Organization, 26: 227-46.

Anderson, Simon, Nisvan Erkal and Daniel Piccinin. 2010 "Aggregative Games with Entry." mimeo, University of Virginia.

Bloom, Nick and John Van Reenen. 2007. "Measuring and Explaining Management Practices Across Firms and Nations." Quarterly Journal of Economics, 122, 4: 1351-408.

Bolton, Patrick and Mathias Dewatripont. 2005. Contract Theory, Cambridge: The MIT Press.

Bonanno, Giacomo and John Vickers. 1988. "Vertical Separation." Journal of Industrial Economics, 36: 257-265.

Bulow, Jeremy, John Geanakoplos and Paul Klemperer. 1985. "Multimarket Oligopoly: Strategic Substitutes and Complements." Journal of Political Economy, 93 (3): 488-511.

Creane, Anthony and Hideo Konishi. 2009. "The Unilateral Incentives for Technology Transfers: Predation (and Deterrence) by Proxy." International Journal of Industrial Organization, 27 (3): 379-89.

Cuñat, Vicente and Maria Guadalupe. 2005. "How Does Product Market Competition Shape Incentive Contracts?." Journal of the European Economic Association, 3, 5: 
$1058-82$.

Czarnitzki, Dirk, Federico Etro and Kornelius Kraft. 2010. "Endogenous Market Structures and Innovation by Leaders: an Empirical Test." mimeo, University of Milan, Bicocca.

Erkal, Nisvan and Daniel Piccinin. 2010. "Welfare-Reducing Mergers in Differentiated Oligopolies with Free Entry" Economic Record, in press.

Etro, Federico. 2006. "Aggressive Leaders." The RAND Journal of Economics, 37 (1): $146-54$.

Etro, Federico. 2007. Competition, Innovation and Antitrust, New York and Berlin, Springer.

Etro, Federico. 2008. "Stackelberg Competition with Endogenous Entry", The Economic Journal, 118: 1670-97.

Etro, Federico. 2009. Endogenous Market Structures and the Macroeconomy, New York and Berlin, Springer.

Etro, Federico. 2010. "Endogenous Market Structures and the Optimal Financial Structure." Canadian Journal of Economics, 43 (4): 1333-52.

Etro, Federico. 2011. "Endogenous Market Structures and Strategic Trade Policy." International Economic Review, in press.

Etro, Federico and Michela Cella. 2010. "Equilibrium Principal-Agent Contracts." WP 180, Dept. of Economics, University of Milan, Bicocca.

Etro, Federico and Ioannis Kokkoris Eds. 2010. Competition Policy and the Enforcement of Art. 102, London, Oxford University Press.

Fershtman, Chaim and Kenneth Judd. 1987. "Equilibrium Incentives in Oligopoly." The American Economic Review, 77 (5): 927-40.

Fudenberg, Drew and Jean Tirole. 1984. "The Fat Cat Effect, the Puppy Dog Ploy and the Lean and Hungry Look." The American Economic Review, Papers and Proceedings, 74 (2): 361-68.

Fumagalli, Chiara and Massimo Motta. 2006. "Exclusive Dealing and Entry, when Buyers Compete." American Economic Review, 96 (3): 785-95.

Gal-Or. 1985. "First Mover and Second Mover Advantages." International Economic Review, 26 (3): 649-53.

Gérard Gaudet and Ngo Long. 1996. "Vertical Integration, Foreclosure, and profits in the Presence of Double Marginalization." Journal of Economics 85 Management Strategy, 
5 (3): 409-32.

Grossman, Sanford and Oliver Hart. 1986. "The Costs and Benefits of Ownership: A Theory of Vertical and Lateral Integration." Journal of Political Economy, 94, 4: 691-719.

Hackner, Jonas. 2003. "Vertical Integration and Competition Policy." Journal of Regulatory Economics, 24 (2): 213-22.

Hart, Oliver. 1995. Firms, Contracts, and Financial Structure, Oxford: Clarendon Press

Hart, Oliver and John Moore. 1990. "Property Rights and the Nature of the Firm." Journal of Political Economy, 98, 6: 1119-58.

Holmstrom, Bengt and Paul Milgrom. 1991. "Multitask Principal-Agent Analyses: Incentive Contracts, Asset Ownership, and Job Design." Journal of Law, Economics and Organization, 7: 24-52.

Holmstrom, Bengt and Paul Milgrom. 1994. "The Firm as an Incentive System." The American Economic Review, 84 (4): 972-91.

Klein, Benjamin, Robert Crawford and Armen Alchian. 1978. "Vertical Integration, Appropriable Rents, and the Competitive Contracting Process." Journal of Law and Economics, 21 (2): 297-326.

Kováč, Eugen, Viatcheslav Vinogradov and Krešimir Žigić. 2009. "Technological Leadership and the Persistence of Monopoly under Endogenous Entry: Static versus Dynamic Analysis." Journal of Economic Dynamic \&3 Control, forthcoming.

Laffont, Jean-Jacques and David Martimort. 2002. The Theory of Incentives: The Principal-Agent Model, Princeton: Princeton University Press.

Martimort, David. 1996. "Exclusive Dealing, Common Agency, and Multiprincipals Incentive Theory." The RAND Journal of Economics, 27, 1: 1-19.

Martin, Stephen. 1993. "Endogenous Firm Efficiency in a Cournot Principal-Agent Model." Journal of Economic Theory, 59: 445-50.

Miller, Nolan and Amit Pazgal. 2001. "The Equivalence of Price and Quantity Competition with Delegation." The RAND Journal of Economics, 32 (2): 284-301.

Motta, Massimo. 2004. Competition Policy. Theory and Practice, Cambridge, Cambridge University Press.

Nalebuff, Barry. 2004. "Bundling as an Entry Barrier." The Quarterly Journal of Economics, 119 (1): 159-87. 
Ordover, Janusz, Garth Saloner and Steven Salop. 1990. "Equilibrium Vertical Foreclosure." The American Economic Review, 80 (1): 127-42

Peitz, Martin. 2008. "Bundling may blockade entry." International Journal of Industrial Organization, 26 (1): 41-58.

Prendergast, Canice. 1999. "The Provision of Incentives in Firms." Journal of Economic Literature, 37 (1): 7-63.

Raith, Michael. 2003. "Competition, Risk, and Managerial Incentives." The American Economic Review, 93 (4): 1425-36.

Rey, Patrick and Joseph Stiglitz. 1995. "The Role of Exclusive Territories in Producers' Competition." The RAND Journal of Economics, 26: 431-51.

Segal, Ilya and Michael Whinston. 2000. "Exclusive Contracts and Protection of Investments," The RAND Journal of Economics, 31 (4): 603-33.

Salinger, Michael. 1988. "Vertical Mergers and Market Foreclosure." Quarterly Journal of Economics, 103 (2): 345-56.

Shaffer, Greg. 1991. "Slotting Allowances and Resale Price Maintenance: A Comparison of Facilitating Practices." The RAND Journal of Economics, 22: 120-35.

Sklivas, Steven. 1987. "The Strategic Choice of Managerial Incentives." The RAND Journal of Economics, 18 (1): 452-58.

Sundaram, Anant, Teresa John and Kose John. 1996. "An Empirical Analysis of Strategic Competition and Firm Values. The case of R\&D competition." Journal of Financial Economics, 40, 459-86.

Sutton, John. 1991. Sunk Costs and Market Structure, Cambridge, The MIT Press.

Tesoriere, Antonio. 2008. "Endogenous Timing with Infinitely Many Firms." International Journal of Industrial Organization, 26 (6): 1381-88.

Vickers, John. 1985. "Delegation and the Theory of the Firm." The Economic Journal, 95, 138-47.

Whinston, Michael. 1990. "Tying, Foreclosure and Exclusion." The American Economic Review, 80 (4): 837-59.

Williamson, Oliver. 1979. "Transactions-Cost Economics: The Governance of Contractual Relations." Journal of Law and Economics, 22 (2): 233-62.

Wright, Julian. 2009. "Exclusive Dealing and Entry, when Buyers Compete: Comment." American Economic Review, 99: 1070-81. 